\title{
A Brief Analysis of the New Trend of International Tax Planning-TESCM
}

\author{
Xianping Yuan, Xiaomei Ma* \\ School of Xi'an University of Science and Technology, Xi'an, China \\ Email: ${ }^{\star} 13209852899 @ 163 . c o m$
}

How to cite this paper: Yuan, X.P. and Ma, X.M. (2018) A Brief Analysis of the New Trend of International Tax Planning-TESCM. Open Journal of Social Sciences, 6, 52-61. https://doi.org/10.4236/jss.2018.62005

Received: January 12, 2018

Accepted: February 6, 2018

Published: February 9, 2018

Copyright $\odot 2018$ by authors and Scientific Research Publishing Inc. This work is licensed under the Creative Commons Attribution International License (CC BY 4.0).

http://creativecommons.org/licenses/by/4.0/

(c) (i) Open Access

\begin{abstract}
With the process of economic globalization, the tax authorities of all countries pay more attention to the protection of the tax base and the contention of the tax sources. In this context, MNCs continue to optimize their global supply chain management and integrate tax optimization into it. Now, the tax efficient supply chain management (TESCM) is the most popular new supply chain planning concept in the world. This paper will discuss TESCM from the perspective of tax planning of multinational enterprises, analyze its advantages by comparing with traditional planning, and explain the application and influence of transfer pricing in TESCM. Through the study, it is believed that for China, the tax authorities should strengthen the capacity building as soon as possible to prevent and cope with the challenges. At the level of regulation, the state should gradually improve the legislation, management and operation of international tax. In the level of management, the amount and professional quality of managers responsible for international tax should be increased and advanced so that they can deal with complex cases of transfer pricing capably; on the globalization of enterprises, departments should focus on corporate transactions, compliance, rationality and independence. TESCM is both an opportunity and a challenge, which can help multinational enterprises achieve stronger competitiveness.
\end{abstract}

\section{Keywords}

Tax Efficient Supply Chain Management, Multinational, Corporation Transfer Pricing

\section{Introduction}

\subsection{Background}

Some macro and micro conditions promote the emergence of TESCM. These 
factors separately explain its influence on TESCM.

Multinational enterprises' business model has changed in nature nowadays, comparing with that in the 1990s. With the rise of external procurement and the acceleration of globalization, the supply chain is a comparatively optimal way to integrate resources all over the world to product, and in this business process, it can help firms withdraw its capital and obtain profits [1]. Facing the demand of new markets, MNEs must transfer from local market to global market. Moreover, they also need to decentralize the authority to subsidiaries or divisions to increase the management efficiency. Nowadays, the business trend has increased the demand for supply chain tax management. TESCM here is an enterprise tax management method based on the perspective of supply chain.

Along with the economic globalization, national tax authorities are paying more attention to protect its tax base (the basis for calculating the base number of the amount of tax payable) and tax sources (the object of taxation determined by various kinds of taxes). MNEs generally use some ways to decrease and deter its tax, which encroaches the interest of host countries. To prevent this, tax authorities specify a set of transfer pricing methods that are intended to ensure a reasonable allocation of profits among the divisions. Transfer pricing generally refers to large enterprises, especially multinational corporations, which use different tax rates and tax exemption conditions of different enterprises to transfer profits to low tax rates or tax-free branches, so as to minimize the tax revenue of the whole group [2]. In order to ensure the collection of rational tax for MNEs, every country's authorities have been focusing on this increasingly.

In the level of transfer pricing rules, the OECD makes new reports and guidelines. The change of transfer pricing rules provides a more comprehensive and strict supervision system to MNEs in the continuing economic crisis. Furthermore, the OECD also protects the host countries in the aspect of tax-collection management.

Nowadays, China has been a large country of attracting a lot of companies of other countries and possessing lots of own enterprises to go out. It is encountering two problems for its double roles. As a host country, it should strengthen its administration for MNEs to protect its own tax base and source. On the other hand, it also plays a role of home country and should learn how to plan its company's tax.

\subsection{Purpose of the Essay}

Most literature is focused on the redesign of supply chains. The tax planning may be only one aspect of this process, and most scholars viewed it as a new concept of supply chain management. On the other hand, it is also a new concept of international tax planning. So, this essay will introduce and discuss TESCM from the perspective of tax planning of MNEs. And, because transfer pricing (TP) is an important method for international tax planning as so far, and also the core of TESCM, so I will explain the impact and application of TP in TESCM. 
This essay introduces TESCM-a new idea in the process of international tax planning, explains some theories and analyzes its advantages by comparing with traditional planning. Moreover, based on this and the rapid development of China, it summarizes the suggestions for enterprises and tax authorities of China in facing the new pattern.

\subsection{Structure}

The rest of the paper is organized as follows. A theoretical framework of TESCM of international tax planning is in Section 2. Section 3 is methodology of this essay-an interview. Section 4 contains some implications of this new trend. Section 5 is the conclusion of this essay.

\section{Theories}

\subsection{International Tax Planning}

\subsubsection{The Concept of International Tax Planning}

International tax is that two or more than two countries government overlap multinational taxpayers' tax crossly for their transnational income or property relying on its political power, forming tax allocation relations between countries.

International tax planning is that in the situation of international tax, in order to ensure and realize maximum interest, multinational taxpayers utilize open and legal manner to reach the purpose of avoiding and decreasing tax burdens. It is a phenomenon of arranging operation activities properly by making use of the international tax preferences or other favorable tax policies. But there is a fatal principle that MNEs must abide by the regulations of host countries in the process of international tax avoidance.

\subsubsection{The Importance and Meaning of International Tax Planning}

Tax planning is a important and meaningful project for MNEs. At the same time, it is also a complex and tough work to do.

Tax planning can minimize MNEs' tax burden and increase profits in some extent. In the level of internal management, it helps to enhance operation management. In the industry level, it also contributes to optimize industrial structure and investment direction. On the other hand, it also has active effective on host countries' tax management.

\subsubsection{The Common Ways of International Tax Planning}

There are many ways to realize international tax planning. The first one, transfer pricing, is a most common way. There are also three ways to implement transfer pricing in the process of intra-trade to relive tax duty as follows: by controlling the purchase and sales price; by international lease; through providing services, use and transfer of intangible assets of associated enterprises.

Second, use international tax havens. International tax havens provide favorable tax situation for MNEs. Third, make use of the regulation of tax deferral. Tax deferral can help the transfer of profits from subsidiaries to parent firms. Fourth, 
choose favorable forms of enterprise organization. Subsidiaries and divisions have different functions for tax planning.

\subsubsection{Principles of International Tax Planning}

The principle of legitimacy: international tax planning activities of multinational corporations must strictly abide by national laws and international tax treaties, and can not violate or violate relevant laws and regulations, as well as international tax provisions.

The economic principle: tax planning activities of multinational corporations should not only reduce the tax burden of single subsidiary companies and overseas branches, but also affect the implementation of global business strategy and sacrifice their overall interests without obtaining tax benefits.

The principle of planning: this principle requires the headquarters of transnational corporations to make detailed and unified arrangements for their international tax planning activities, and check and adjust them at the right time, so as not to conflict with or conform to the economic principles of the relevant tax laws and international tax treaties.

\subsection{TESCM}

\subsubsection{The Concept of TESCM}

Supply chain is that multinational enterprises will make the suppliers, manufacturers, distributors, retailers, and final users a integral function network structure around core enterprises. It is not only a chain of logistics, information and capital connecting suppliers with final users, but also a chain of value-added: materials are added value for the processes of being manufactured, packed, transported and so on. Consequently, it will bring income and profit for involved firms on the same chain.

When enterprises are operating cross-bordered, they can optimize the tax in the business change process, which can maximize the total value of conglomerate supply chain. It is an integration of tax-optimization with supply chain management. This kind of pattern of international tax planning is the most epidemic and new planning idea internationally. This is the internal meaning of tax effective supply chain management (TESCM). Specifically, the tax of supply chain management is refers to the enterprise through their own tax management and enterprises of supply chain collaboration, cooperation and use modern technology to the whole supply chain of tax cost and tax risk overall planning and the whole supply chain can be synchronized operation activities. This requires enterprises to collect, collate and analyze the tax policies designed by the upstream and downstream suppliers, and apply them to the whole process of tax administration in enterprises [3].

\subsubsection{The Method of TESCM}

Transfer pricing is the core method of TESCM. A multinational company generally involves many complicated and common business aspects, such as loss allo- 
cation, corporate restructuring, transfer of intangible assets and international finance. These are correlated closely with transfer pricing.

With the development and evolution of SC, MNEs are facing more challenge in the management of transfer pricing. The benefits of transfer pricing that it can bring crucial value and future growth potential to business projects has stimulate the firms to improve and innovate new planning pattern.

\subsubsection{The Features of TESCM}

TESCM has three distinctively main features as follows. These features explain why it turns into a new idea of international tax planning in some extent.

First, it belongs to driving supply chain planning. The objective of supply chain is to pursue value-added, create more profit and manage more efficiently. The tax planning integrated with supply chain is coherent with these objectives, which will reduce the tax cost and increase profits in a greater degree. It will be a driving force for firms to redesign SC.

Second, tax compliance requirements are consistent with the needs of the business on this chain. To implement this new way effectively, one of the most is to abide by the regulations about tax management of host countries when make tax planning strategies. The opportunities of tax planning come from the business process. So, it is crucial for MNEs to balance the tax requirements and business demands.

Third, the risks of supply and value chains and the concentration of intangible assets make most of profits accrue to the main stakeholders. For example, the subject company (commission agents, shared service center, limited risk distributor), moderately stable profits belongs to limited stakeholders.

\subsection{Transfer Pricing}

\subsubsection{The Definition of TP}

Transfer pricing refers to the pricing of intermediate product or service (tangible or intangible) that is transferred between two divisions (or affiliates, subsidiaries or departments) within a MNE. The price is an internal price.

\subsubsection{The Function of TP in the Process of International Tax Planning}

With globalization, it is increasingly common that intermediate and final products are exchanged between the different subsidiaries of a global firm. If the involved subsidiaries are in different countries then transfer pricing is viewed as a powerful tool for shifting income to subsidiaries in lower-tax countries and consequently increasing after-tax profit. In different host countries, the tax rate and categories are diverse.

When a global firm has many subsidiaries in different places and it has achieved a high revenue in a higher tax rate area, how can it make use of the favorable tax policies in other regions to reduce its tax. So, transfer pricing is playing a significant function in this situation. That is, this firm can transfer its revenue or profit through intra-trade, the pricing decision is a core of this 
process. Transfer pricing is a main and direct way in international tax planning.

\subsubsection{The General Method of TP}

There are two methods of transfer pricing: one is based on the basis of "cost increase" and the other is determined by the "negotiated price" of the buyers and sellers. The former has a close relationship with the internal cost; the latter is a broad strategic limit. The key factor in deciding what pricing is to be used in international transactions is whether the buyer can get the product from the outside. If the external market does not exist, the "cost increase" formula is popular, negotiated prices or higher than market prices, or lower than market prices, between the maximum supply price and the minimum purchase price. The actual transfer pricing system must be linked to the budget or profit target of a specific subsidiary so as to maintain the power of management. If the transfer pricing method affects the profit of a particular branch, the other standards other than the profit must be taken as its operating target. It is very complex to implement the cost pricing method, which is based on the internal cost or the external market price. The first case, if the transfer of production from one stage to the next stage, the transfer unit is a cost center, according to the cost to determine the transfer price basis; if the unit is a profit center, is the cost plus a percentage of the gross profit as the pricing basis; in the same production unit lateral transfer, usually the cost plus management fees as the pricing basis. In the latter case, the actual market price from the international market is generally used as the basis for pricing. Similarly, the determination of the negotiated price is also very complex. For example, the determination of technology transfer prices is very arbitrary, but ultimately depends on the ability to bargain.

\section{Case and Interview}

\subsection{A Simplified Case}

In this part, I will use a case and an interview to present what is TESCM, and the differences with traditional idea.

A quantitative comparison of multinational company's income, cost, tax and profit when utilizing traditional planning and TESCM, as shown in Figure 1.

From the picture above, we can know the firm's income, cost, tax and profits indifferent conditions. Contrast to current conditions, under only tax optimization, its tax decreases and profit increases; under only SC optimization, its cost of SC reduces and results to profit augment; under TESCM, its has both effects of other methods and generate a more favorable effects-profit growth to 98.28\%. This is a obvious reflection of efficiency of TESCM. At the same time, for in the process of TESCM, managers will analyze tax and operation risks, so, this planning can minimize risks all over the world.

\subsection{An Interview}

This interview on the director of KPMG-Gejun Rao global transfer pricing 


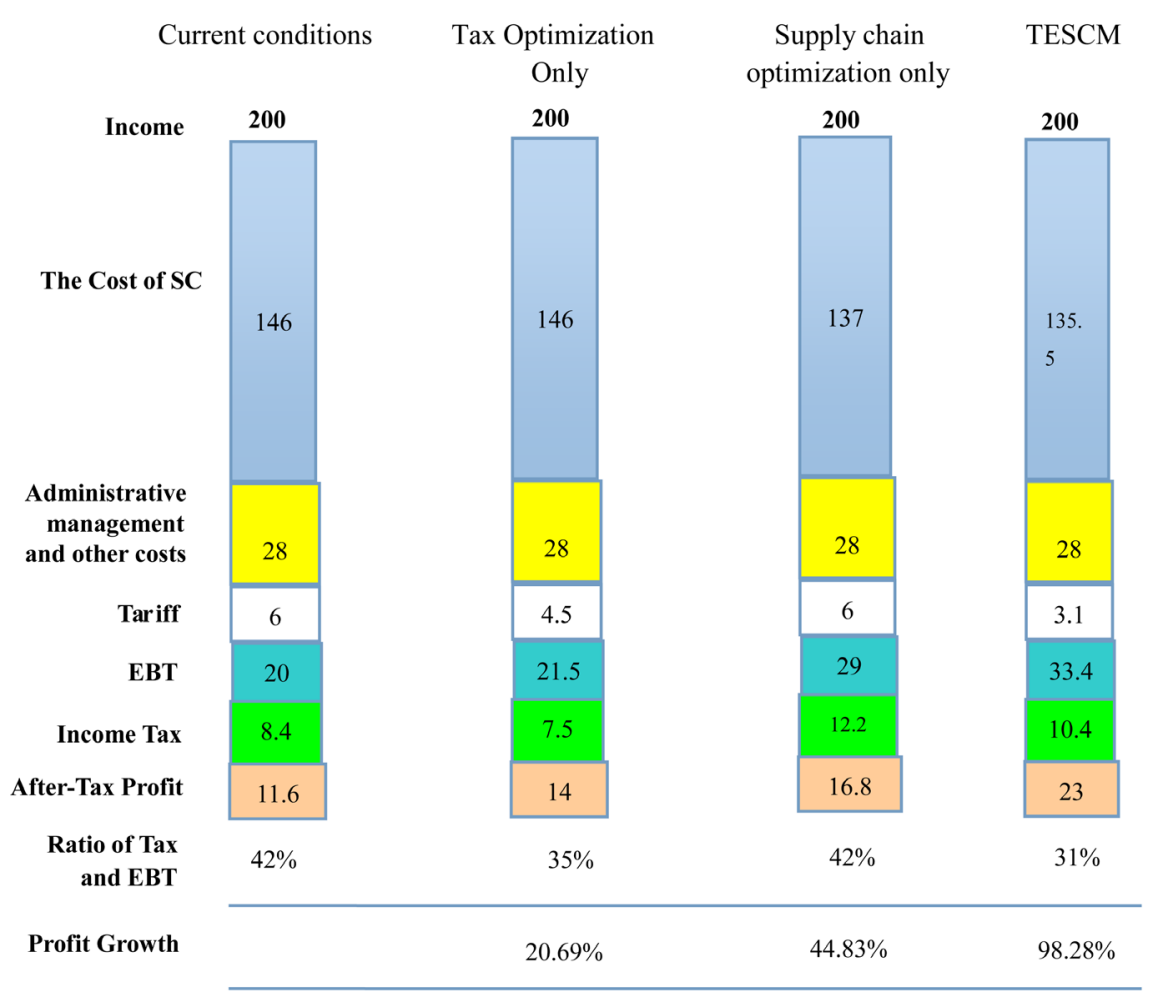

Figure 1. Comparison between traditional planning and TESCM.

services discusses the emergence of TESCM, a simple introduction of the complete process of TESCM, and a comparison with traditional planning method.

When they are operating internationally, MNEs will locate R\&D, procurement, production, distribution and management in different places to lower the cost and meet the business needs as possibly. From the perspective of practice, TESCM includes five business processes as follows: 1) Evaluation phase or feasibility analysis: evaluate the applicability for the conglomerate, review the current model and tax structure of the conglomerate and identify important commercial and tax interests and risks to determine if TESCM should be implemented. 2) Initial design stage: develop TESCM model initially, design and carryout original plan. 3) Elaboration phase: define specific model and formulate specific implementation plan. 4) Executive phase: the typical process is RICE. 5) Monitoring phase: track and assess the comprehensive effect.

Compared with traditional tax planning idea, TESCM emphasizes the coordination management between more taxes, links and whole process, and distribute reasonable profits in different countries with different tax rate using transfer pricing as a main measure.

The conglomerates can make significant decisions through main company of SC, and this main body will undertake more functions of commercial procurement agreement, stock management and marketing as possible, while other firms assume less functions and risks. Consequently, the majority of profit of SC belongs to the main firm and pay tax at a relatively low rate. Then, tax burdens 
of whole conglomerates are optimized, and shareholders' value realize maximization. Furthermore, they meet the tax requirements of other countries and have a good control of tax risks.

Transfer pricing and SC decisions are highly correlated. Tax-aligned design and management of SC are poised to be a new frontier of excellence for global companies which have recently recognized that significant savings can be achieved if transfer pricing and SC activities are coordinated effectively.

Traditionally, the utility of transfer pricing is just within the MNEs, mainly used to shifting income and produce more after-tax savings for the conglomerate. Now the TESCM provide a new perspective for global companies. The tax planning can be incorporated in the management of SC. It also offers a combination of tax planning between suppliers, core firms, factories and retailers, and can promote them to realize value maximization and tax minimization of the whole firms on the same supply chains.

\section{Discussion}

\subsection{Benefits of TESCM}

From the last part's figure, we can see TESCM is an integration of tax optimization and SC optimization. The effect it exerts is bigger than any of those based on the both reduction of tax and cost of SC. At the same time, it is also a transfer and development of tax planning perspective. The traditional planning just takes only one firm into account. However, TESCM is a consideration of win-win and collaboration, which set a goal of reducing all relevant companies tax burdens.

The consideration of tax planning in the design of SC is a way to optimize the operation and management. It can not only maximize the value of main company but also contribute to the value-maximization of whole SC.

In some extent, it can be identified as a strategy for a commercial alliance. Value creation may be its spirit and value-maximization of customers is consistent with SC's value-maximization inherently.

\subsection{Risks of TESCM}

TESCM also has risks as other planning patterns, which requires enterprises to analyze carefully. TESCM is a complicated management method, involves many kinds of tax. Consequently, it needs lots of detailed works and will consume a lot of human resources. In this process, the biggest risk is that the firm's business cannot completely be carried out according to the established management solutions leading to the disconnection between given transfer pricing arrangements and practical business model. Finally, this firm will be recognized as having unreasonable commercial purposes, lacking management essence and forced to make tax adjustment, which maybe bring double taxation risks to the firm.

Of course, there are risks to use transfer pricing in TESCM. National tax authorities will check the rationality of this price. Anyway, a company could 
choose to determine the TP by any method as long as it can justify its use to the authorities. It is a important principle for MNEs to exert transfer pricing successfully.

How should we do to decrease these risks? In the angle of risks sources, we should analyze the risks carefully and in detail initially, which requires us to learn the firms completely. Coordinating the workers, designers and managers of every firm on this SC is a important and essential project. The implementation of TESCM relies on cooperation of each department. Regulation is an effective way to ensure TESCM is carried out successfully. More importantly, multinational enterprises must ensure the compliance and rationality of their planning, which is the fundamental way to control risks.

\subsection{Development of TESCM in the Future}

TESCM is a new idea, which emerges lately under the current conditions of economic development and regulations. Though it has some risks to enterprises and authorities, TESCM also has active influence on the global development and management of MNEs, which is incontrovertible. The risks can be controlled and the globalization will promote its sustained development.

\section{Conclusion}

\subsection{Implications of TESCM for Chinese Tax Authorities and Companies}

Facing the new trend, what should tax authorities of China do or what attitude should they have? And, what measures should Chinese MNEs take to tackle this challenge if they want to try this?

As tax authorities of China, they should strengthen capability contribution, take precautions and deal with challenges as soon as possible. In the level of regulations, authorities should increasingly complete the legislation, management and operation of international tax. In the level of management, the amount and professional quality of managers responsible for international tax should be increased and advanced so that they can deal with complex cases of transfer pricing capably. Meanwhile, the fair and stable environment is important as well.

In a word, the tax authorities of China should protect Chinese tax base in one hand and create a harmonious and apparent tax environment also.

If Chinese companies want to try TESCM, they should consider deep contact with tax authorities initially and then pay more attention on four questions: 1) The effects of complex VAT and tariff on TESCM; 2) Whether the established main firm is recognized as permanent establishment easily; 3) Whether tax authorities' view of some aspects has differences with the guidelines of OECD; 4) Host countries' some rules about retained profits overseas.

Whatever, Chinese authorities and companies are involved in this reform which is crucial for both. So, the necessary adjustment should be taken and implemented promptly. 


\subsection{Effects on Globalization}

TESCM happens in the situation of globalization. In reverse, it also will promote the process of globalization. Nowadays, related transactions have reached $50 \%$ of the amount of global trade, and the redesign of SC becomes more complicated increasingly. So, TESCM raises more requirements for MNEs in either global operation or management and for tax authorities in the supervision over MNEs and protection for rate base and sources. The effective establishment and implementation of TESCM is a vigorous and powerful driver for globalization. It can not only accelerate the globalization but also enhance the quality and degree of globalization.

TESCM is a new challenge and provides a new thinking for MNEs operation and management. For authorities, they should focus on the compliance, rationality and independence of enterprises' connected transactions. It provides MNEs chances to develop internationally and use global SC. Cooperation with other companies, such as suppliers, retailers and so on, will be in favor of the integration of global resources and enhance the efficiency.

TESCM is both a challenge and opportunity. Making good use of it may help MNEs stand in the world much longer and more competitive.

\section{References}

[1] Gao, Y. (2014) TESCM: Today's New Trend in Tax Planning for Multinational Corporations-An Interview with KPMG (China), Director of the Global Transfer and Pricing Service. Rao Gaojun, International Tax.

[2] Huang, L.J. (2017) International Tax Planning Strategy of Transnational Corporations Study. Finance and Accounting, 18, 149, 151.

[3] Xie, Z.B. (2015) Research on Enterprise Tax Management. Jinan University, Guangzhou. 